\section{LOS ÚLTIMIOS CINCUENTA AÑOS}

Es curioso que, a pesar de la importancia social y política que ha planteado el terrorismo en los últimos cincuenta años, sobre todo en España, este fenómeno ha tenido una repercusión pequeña en el terreno de la ficción, tanto en el cine como en la literatura, si se tiene en cuenta que durante la década de 1980 y 1990, el terrorismo, en el caso español, era una noticia que abría los telediarios de cada día y presentaba unas cifras de asesinatos y crímenes verdaderamente abrumadoras. Sólo en 1980 ETA mató a 91 personas. Un estudio encargado por Juan José Rosón, Ministro del Interior de UCD, presentaba la frecuencia con que ETA aparecía en la información nacional en comparación con los tres principales partidos democráticos: UCD, PSOE y PCE. UCD ocupaba un poco más de espacio que el PSOE y ambos el doble que el PCE, pero ETA había conseguido más tiempo de informativos que la suma del
PSOE y UCD. A su vez, cada noticia de uno de estos partidos producía un escaso eco en los días siguientes, mientras que las noticias proporcionadas por ETA cuadriplicaban esa repercusión, con la cual la conclusión parece evidente: ETA ganaba la batalla (Rosón, 1984; Domínguez, 2003).

Un estudio realizado en 1988 por la agencia Vasco Press, sobre la imagen del País Vasco en la prensa de Madrid, confirmaba la presencia mediática del terrorismo. El 38,81\% de las noticias publicadas en diarios nacionales sobre el País Vasco tenían como tema la violencia, muy por encima de la política $(24,7 \%)$ y de la economía $(16,02 \%)$ y sobre todo de la cultura $(3,64 \%)$. La conclusión del estudio señalaba en que uno de cada tres mensajes referidos al País Vasco tenía como protagonista al terrorismo. Años después, durante la primera década del siglo XXI, fue el terrorismo islamista el que ocupó portadas de periódicos y las parrillas informativas de todo el mundo, a partir de los atentados del 11 de marzo en

\footnotetext{
${ }^{1}$ Luis Veres nació en Valencia en 1968. Es Doctor en Filología Hispánica y Licenciado en las especialidades de Lengua Española Literatura Española y Filología Valenciana. Ha sido profesor invitado en universidades de Perú, Polonia, Austria, Francia, Italia, Holanda, Rumanía, Reino Unido y Portugal. De 1996 a 2009 fue profesor de Teoría del Lenguaje y Crítica Literaria en la Facultad de Ciencias de la Información de la Universidad Cardenal Herrera-CEU (Valencia). Desde 2010 es profesor en el Departamento de Teoría de los Lenguajes de la Universidad de Valencia. Es autor de las novelas El hombre que tuvo una ciudad y El cielo de cemento, así como de los ensayos, La narrativa del indio en la revista Amauta, (2001), Periodismo y literatura de vanguardia en América Latina (2003), Literatura e imaginarios sociales (2003), Estrategias de la desinformación (2004), La retórica del terror (2006), Los reyes y el laberinto, Sobre Borges, Lugones y otros ensayos (2007), Entre la Cruz y la Media Luna (2007) y El sentido de la metaficción: de Woody Allen a Roberto Bolaño. Ha ganado el premio de novela Vicente Blasco Ibáñez y el Juan Gil-Albert de ensayo. E-mail: Luis.Veres@uv.es

2 Este trabajo se incluye dentro del proyecto de investigación financiado por la Universidad de Valencia titulado "Terrorismo y cine: de una perspectiva histórica a la problemática global" UV-INV-PRECOMP12-80758.
} 
la estación de Atocha en Madrid (Veres, 2006).

En esta situación sorprende una cuestión fundamental: aunque este interés mediático por el terrorismo, resulta verdaderamente curioso el escaso reflejo que el terrorismo ha tenido en el terreno de la ficción, tanto literaria como cinematográfica. Ese es un fenómeno que se agudiza en España frente a otras cinematografías como la norteamericana, a pesar de la presencia constante de grupos como ETA o GRAPO en los años de la Transición y en los años de la democracia consolidada en España. También es curioso que el atentado más brutal de la historia de España, ocurrido el 11 de marzo de 2004, tenga una escasa presencia, prácticamente inexistente en el cine, y muy reducida en la literatura.

En estas circunstancias sería de esperar que, a causa de su trascendencia en el caso español, el terrorismo hubiera constituido una preocupación importante tanto en las obras de ficción de novelistas, como de cineastas, pero el resultado suena contradictorio. Sólo unas cuarenta películas desde 1977 recogen tramas insertas en el problema del terrorismo vasco. Para Santiago de Pablo esa cantidad es grande (2010: 144) y es cierto si se tiene en cuenta el volumen del cine español, pero es pequeña si se atiende a la presencia del terrorismo en el agenda informativa española en los últimos cincuenta años.

\section{Un retrato histórico}

En relación con el terrorismo, el cine español ha tratado de confeccionar en la mayoría de los casos un retrato histórico de los hechos. La protagonista, en la mayoría de los casos, ha sido la tristemente conocida banda terrorista ETA a causa del gran número de atentados con que ha amedrentado a la sociedad española durante los últimos cincuenta años (Elorza, 2000; Ezquerra, 2003). Pocas películas, como Sé quién eres (2000) de Patricia Ferreira o La soledad (2007) de Jaime Rosales,renuncian a identificar el grupo terrorista del que hablan para centrarse en una circunstancia más general. Por otra parte no existen películas sobre los GRAPO $\mathrm{u}$ otros grupos terroristas como Terra Lliure, el Exercito Guerrilero Gallego o el FRAP, aunque en la película La noche más larga (1991), de José Luis García Sánchez, hubiera referencia a ellos.

La actitud documental pervivió en los años ochenta con películas como Euskadi hors d'État (1983) de Arthur Mac Caig y Días de humo (1989) de Antxon Eceiza. Incluso películas históricas vascas ambientadas en otra época recibían lecturas simbólicas: Akelarre (1983) de Pedro Olea, La conquista de Albania (1983) de Alfonso Ungría o Mina, Viento de libertad (1977), de Antxon Eceiza, en la que aparece el himno nacionalista vasco (De Pablo, 2010: 155).

Películas como Camada negra (1977) de Manuel Gutiérrez Aragón, La fuga de Segovia (1981) de Imanol Uribe, Yoyes, (2000) de Helena Taberna o Lobo (2004) de Miguel Courtois, prestan atención a determinados periodos representativos de la historia de ETA. Quizás la más interesante resulte Yoyes, ya que fue la primera película que se atrevió a denunciar las disidencias internas de la banda terrorista. La película narra la historia de Dolores González Catarain, que fue uno de los primeros miembros de ETA en 
atreverse a abandonar el grupo terrorista. ETA decidió asesinarla el 10 de septiembre de 1986 en Ordizia, localidad natal de la víctima, ante la presencia de su hija.

\section{La historia dell cine español}

Algunas películas como Ander eta Yul (1983) de Ana Díez, junto a algunos documentales como $L a$ resistencia vasca contra el franquismo (1977) o Ama Lur (1968) de Carlos Roldán Larreta, plantean propuestas justificativas sin presencia de crítica al fenómeno terrorista y a los asesinatos de una banda, que fue la principal causa de violencia armada durante la segunda mitad del siglo XX. Otras películas ambientan su trama en relación con atentados terroristas reales como La muerte de Mikel (1983) de Imanol Uribe, El pico (1983) de Eloy de la Iglesia, Días contados (1994) de Imanol Uribe o la reciente No habrá paz para los malvados (2011) de Enrique Urbizu, acerca del gran atentado del terrorismo islamista en la estación de Atocha de Madrid. Curiosamente, todas ellas tuvieron excelentes resultados de taquilla.

Posiblemente, de todas estas películas, la más significativa sea Días contados, obra que durante varios años representó la muestra más valiente al retratar la historia de ETA, tema que en cierto modo era tabú hasta entonces. La película, basada en la novela del mismo título de Juan Madrid, publicada un año antes, abre el cine del siglo XXI en este asunto. Lo más sorprendente, dentro de la libertad que supone la adaptación cinematográfica reside en que, mientras que en la película el fundamento de la trama gira alrededor de la preparación de un atentado de ETA y la presencia del mundo de un comando terrorista, en el barrio de Malasaña, en la novela todo ello no presenta ni el más mínimo rastro.

De gran trascendencia en la historia del cine español es un documental sobre ETA y la situación del País Vasco que suscitó una intensa polémica. Se trata de La pelota vasca, La piel contra la piedra (2003), del realizador Julio Médem. La pelota vasca tiene una realización impecable, pero, si entendemos el documental como el género de lo real (Nicholls, 1997: 7 y ss), lo es mentiroso. ¿Y por qué? En primer lugar, porque se lo realizó en unas condiciones difíciles. Una parte de los implicados en el conflicto: dirigentes del Partido Popular y representantes de las víctimas de ETA se negaron a aparecer en un video que otorgara la misma veracidad a sus testimonios que a los de personas que simpatizaban o defendían la postura del grupo terrorista, como Arnaldo Otegui, dirigente de Herri Batasuna. Como consecuencia, la película resultaba ya imposible, puesto que dejaba al film sin una parte de los testimonios, con lo cual se daba una situación muy similar a si se hubiera realizado un documental, sobre los campos de exterminio nazis, sin la presencia de los testimonios de las víctimas, mientras que el grueso de la película estuviera formado por las palabras de militantes del partido nazi, representantes de las SS y carceleros de los mismos campos. A ello se unen algunas cuestiones numéricas: son más numerosos los testimonios de la causa del nacionalismo radical; también es más larga la intervención de los testimonios de esta parte del conflicto; y, finalmente, el montaje, como en todo documental es decisivo $\mathrm{y}$, en este caso, bascula hacia la 
simpatía o, al menos, la comprensión del conflicto y la justificación, en cierta medida, del terrorismo. Intentar comprender un conflicto es distinto de intentar justificarlo, y eso fue lo que hizo Julio Médem. Ante la contemplación de los hechos, se puede ser testigo, pero también se puede ser colaborador.

Como consecuencia del asesinato del concejal del PP Miguel Ángel Blanco, en la ciudad alavesa de Ermua, el 13 de julio de 1997 y las treguas de ETA, en los años 1998 y 1999, el interés por el terrorismo aumentó desde el cine. También hay que tener en cuenta que disminuyó la presión social de la banda y el temor que la población le tenía. También creció la indignación ante su barbarie. Surgieron, así, películas como A ciegas (1997) de Daniel Calparsoro, rodada antes del asesinato de Blanco y cuya lectura conduce a cierta ambigüedad. También se realizaron documentales como Sin vendas en la memoria (2008) de Manuel Palacios o Corazones de hielo (2007), ambas producidas por las asociaciones de víctimas existentes en España.

La lucha del terrorismo de Estado quedó representada por películas como El caso Almería (1984), GAL (2003) y la mencionada Lobo (2004) de Miguel de Courtois. De una interpretación ecléctica del problema vasco, se pasó a una interpretación crítica que se vio reflejada, como consecuencia de la cruenta evolución del terrorismo vasco, en el género documental: desde La pelota vasca (2003) hasta el cine de Iñaki Arteta con El infierno vasco (2008) o Nada será igual (2010).

Un vistazo a los títulos basta para observar que el grueso del cine español, que versa sobre asuntos relacionados con el terrorismo, se ha centrado en el problema vasco y la presencia de los crímenes de ETA a lo largo de la historia de España, mientras que el terrorismo islamista ha quedado prácticamente ausente de toda mención en el cine español. La razón de esta ausencia puede radicar, en primer lugar, en el número de atentados: ETA adelanta al terrorismo islamista con mucho en materia de realización de atentados. La perduración de los crímenes de ETA proporciona fácilmente un buen corpus de materia para ficción. Por otra parte, el dramatismo de los hechos, en el fuerte dolor causado por los atentados de Atocha, cuya repercusión supera la producida en los atentados en Rabat contra la Casa de España, en mayo de 2003, supone, al igual que en el caso norteamericano, que tanto narradores como cineastas no se hayan atrevido a adentrarse en dichos sucesos por miedo a herir susceptibilidades o por temor a no tratar el tema con la debida eficiencia. Algo que podría ser explicable en un principio, en los primeros años. Pero, tras una década, las muestras son mínimas en comparación con el caso norteamericano, que dio muestras desde los primeros meses después de la catástrofe del 11 de Septiembre.

Circunstancias diferentes son las que afectan al cine sobre ETA. Obviamente éste no se pudo realizar hasta los inicios de la democracia. Después, su escasa recurrencia no puede encontrar otra explicación que el miedo. ETA asesinó a periodistas, jueces, policías, militares y ciudadanos corrientes (Calleja, 2002). Todo el que estaba contra él era un objetivo del terrorismo y ello es razón, más que suficiente, para que no se diera tal visión de los hechos. Una película que 
simbólicamente apunta en algunos momentos a ETA es Sé quién eres (2000) de Patricia Ferreira, que se centra en las consecuencias de un atentado durante la Transición y que durante mucho del tiempo de suspense de la película se sospecha de la autoría de ETA, aunque, finalmente, la investigación demuestra que los autores del atentado son policías infiltrados en un grupo de extrema izquierda cuyo nombre no se explicita.

Se puede decir que las muestras más significativas del cine, en términos realistas sobre ETA, no llegan hasta el año 2000, con El viaje de Arián de Eduardo Bosch. Ambientada en los años ochenta, narra el periplo vital de una joven, Arian, que ingresa en las filas de ETA por medio de su novio Vivaldi. La película se ajusta a la estética realista y ese mismo realismo sirve para retratar con fidelidad la situación del País Vasco y el grupo terrorista. La película pasa revista a los escenarios del terrorismo, desde los locales de Jarrai- las juventudes de Herri Batasuna- a los métodos de captación de nuevos miembros para la violencia callejera a la preparación de atentados o el refugio en la frontera francesa. El realismo alcanza su máxima expresión porque retrata con exactitud lo que se sabe de la vida cotidiana de los terroristas y el dolor causado a las víctimas. La historia se desliza hacia la derrota del terrorismo y el desengaño de la protagonista, que intenta huir de las garras de la banda para encontrar finalmente un fatídico destino, que simboliza la historia de la disidencia en ETA.

En el año 2000 surge una sugerente producción, La playa de los galgos de Mario Camus. Ambientada en los años ochenta, se trata de una reflexión sobre la catástrofe personal que rodea las personas insertas en el hecho terrorista, tanto a los que producen el daño como a los que lo reciben, familiares y víctimas. Historia de contradicciones que sigue las convenciones del triller de misterio, narra la historia de un refugiado, Pablo Arketa, que huye de sus propios compañeros de banda terrorista y que, retirado en Noruega, vive obsesionado con que algún día los suyos le den caza. Un día la esposa de una de sus antiguas víctimas, un ingeniero que recuerda la nuclear de Lemoniz, lo encuentra y lo mata tras convertirse en la amante de su hermano. Aunque en ningún momento se nombra ETA, su presencia es evidente, ya que la película se ambienta cerca del País Vasco en Castro Urdiales, provincia de Santander. El film reúne la crítica al terror y las motivaciones que lo mueven en cada uno de nosotros: "Tengo sobrados motivos para odiar a los que usan el terror contra quien no se les somete", dirá uno de los protagonistas, o "la violencia no deja satisfecho a nadie", se repetirá. Y esa crítica queda algo desdibujada al extenderse a todos los que quedan salpicados por el conflicto y no únicamente a sus verdugos.

Caso aparte es la película La soledad (2007) de Jaime Rosales, en la que se muestra, de manera muy distanciada y fría, la casualidad con la que el terror y la catástrofe interrumpen la vida cotidiana de una joven que viaja en un autobús, en el que explota una bomba en el centro de Madrid. El mismo director rueda Tiro en la cabeza, en la que se cuenta el asesinato a manos de ETA de dos Guardias Civiles, Fernando Trapero y Raúl Centeno, que investigaban de incognito a la banda en la ciudad francesa de Capbreton. La película narra en tono muy distanciado el acontecer 
vital de un joven que colaborará en el asesinato, pero lo curioso de la película, que es una constante en su director, es ese seguimiento anodino de lo cotidiano, que, en caso del tema del terrorismo de ETA, conduce a una interpretación muy realista de lo que es la irrupción de la catástrofe en las vidas de las personas.

Posiblemente, la película más interesante de la década, dentro de esta temática, sea Todos estamos invitados (2008) de Manuel Gutiérrez Aragón. Su interés radica en que incluye numerosas novedades acerca de la realidad del País Vasco en relación con el terrorismo que se habían mantenido ausentes en los filmes anteriores. La película narra la historia de un miembro de ETA que durante un atentado resulta herido en un accidente de coche. En su recuperación traba amistad con su terapeuta, la cual es compañera de un profesor de la Universidad de País Vasco, que está amenazado por ETA y que finalmente será asesinado. En ese contexto, la película muestra una radiografía de la sociedad vasca que pone al descubierto la hipocresía de aquellos que, en el entorno social del protagonista, miran hacia otro lado. La película muestra, de este modo, la brecha que se abre en medio de la sociedad y que conduce a una de sus partes a justificar las muertes de sus ciudadanos, para hacer prevalecer sus ideas y su modelo político. La película es interesante porque desvela los entresijos de la vida cotidiana de los amenazados, su dependencia de las escoltas, su autoexclusión social, las molestias que esa compañía supone en comidas, cenas y aulas universitarias. El protagonista interpretado por José Coronado les dirá a sus amigos: "Me felicitáis. Sólo lo hacéis cuando no os ve nadie". También la película muestra la presencia y peso del mundo de ETA en la sociedad vasca, la hipocresía de cierta parte del clero y la dificultad que tienen los sujetos de ese universo para salir de su mundo y para arrepentirse del pasado. Todo ello hace de Todos estamos invitados la mejor muestra de este cine como testimonio ponderado de la realidad vasca en los últimos años de existencia de ETA.

\section{Valentía intelectual para hablar con libertad}

Como se puede observar, la representación del terrorismo de ETA fue un hecho tardío. Si se tiene en cuenta que ETA surge a finales de los cincuenta y que, cincuenta años después, es cuando se comienza a hablar de la banda terrorista y de la situación del País Vasco en el cine sin temor, es explicable la exigencia de una perspectiva histórica y cierto grado de valentía intelectual para hablar con libertad de estos fenómenos, circunstancias inexistentes hasta entonces. Y ello explica la situación que se ha dado en el cine en relación con el 11 de marzo, caso que ha ofrecido raros ejemplos cinematográficos.

La conmoción de esta fecha y los atentados de Atocha, en 2004, han dado varias muestras de valía, que todavía son manifestación de su escasez. Destacan algunos documentales Hay motivo (2004), en el que 32 cortos pretendían hacer una radiografía crítica de la situación de España bajo el gobierno de José María Aznar, la entrada en la guerra de Irak y los atentados del 11 de marzo. Uno de esos cortos está formado por fragmentos de $L a$ pelota vasca de Julio Meden. A él le sigue Madrid: 11 M, Todos íbamos en ese tren 
(2004) que recupera las imágenes de la catástrofe y analiza los motivos de la catástrofe como la participación de España en la guerra de Irak. Un repaso a los hechos: desde los atentados a la derrota electoral de Aznar se da en $11 M$ Cuando la calle habló (2007) de Stephane M. Grueso.

iHay motivo! no se emitió comercialmente en cines, sino que fue proyectado en universidades y otros lugares que solicitaron expresamente su proyección. También se emitió en canales locales de televisión. Los propios cineastas utilizaron estos canales a fin de difundir la serie tan rápido como les fuera posible, por lo que también animaron a descargar la película por Internet. La película fue estrenada comercialmente el día 12 de noviembre de 2004 y proyectada hasta el día 25 del mismo mes, último día de exhibición de la cinta. Apenas 496 espectadores se acercaron al cine para verla (datos del Ministerio de Cultura).

En una línea muy próxima, aunque se trate de cine de ficción, se encuentra la película Ilusiones rotas: $11 M(2005)$ de Alex Quiroga. Pero, lo significativo de estas películas es su escaso rédito de taquilla. Apenas superaron los 500 espectadores (De Pablo, 2010: 146), con lo cual, por sí solo, puede explicar la poca atención que, posteriormente ha suscitado el tema de estos atentados, aunque también hay que tener en cuenta que la realización de un film, sobre este asunto, resulta complicada después de la saturación de imágenes informativas que plagaron los telediarios de los años posteriores al suceso, ya que éstas no se limitaron a los días del atentado, sino que se emitieron durante los años posteriores de investigación del mismo.

\section{Un hecho tardío}

Este recorrido por el cine y la novela en España, que desemboca en el siglo XXI, plantea numerosos interrogantes acerca de lo que va a ser el futuro del relato en los años siguientes. La catástrofe se configura como una fuente de argumentos y un semillero de críticas hacia la sociedad y su silencio, hacia la política y sus gestos de manipulación, hacia el miedo, el terror, la mentira que sufren unos ciudadanos que son sujetos anónimos y que sólo la ficción puede darles cabida. Atentados como los de Atocha o el del asesinato de Miguel Ángel Blanco han marcado de manera determinante la historia de España y de los relatos resultantes de esa misma historia. Por ello creemos que es interesante la indagación del fenómeno terrorista en España, como la manifestación de la catástrofe y la barbarie más actual y moderna en lo que se configura, como la corporeidad de la tragedia contemporánea, como canalización de los miedos y sufrimientos que atenazaron a una sociedad desde el siglo XX al XXI. 


\section{Referências Bibliográficas}

ATXAGA, Bernardo (1994), El hombre solo, Barcelona, Círculo de Lectores. (1997), Esos cielos, Barcelona, Ediciones B. (2003), El hijo del acordeonista, Madrid, Punto de Lectura. (2005), Obabakoak, Barcelona, Ediciones B.

BARRENETXEA, Igor y LÓPEZ DE MATURANA, Virginia (2010), "La conciencia del terrorista", en Gaytán Esther, Gil, Fátima y Ulled, María, (Eds.), Los mensajeros del miedo, Madrid, Rialp.

BERGER, Peter y LUCKMANN, Thomas (1968), La construcción social de la realidad, Buenos Aires, Amorrortu Editores.

CALlEJA, José María (2002), Arriba Euskadi. La vida diaria en el País Vasco, Madrid, Planeta.

CARMONA, L.M. (2004), El terrorismo de ETA en el cine, Madrid, Cacitel.

CARO BAROJA, Julio (1989), Terror y terrorismo, Madrid, Plaza y Janés-Cambio 16.

CERDÁN, Manuel y RUBIO, Antonio (2003), Lobo. Un topo en las entrañas de ETA, Barcelona, Plaza y Janés.

CONTRERAS, Fernando R., y SIERRA, Francisco (2004), Culturas de guerra, Madrid, Cátedra-PUV.

DELUMEAU, Jean (2002), El miedo en Occidente, Madrid, Taurus.

DÍAZ HERRERA, José y DURÁN, Isabel (2002), ETA: el saqueo de Euskadi, Madrid, Planeta.

DÍEZ, Luis Mateo (2007), La piedra en el corazón, Barcelona, Círculo de Lectores.

DOMÍNGUEZ, Florencio (2003a), Dentro de ETA. La vida diaria de los terroristas, Madrid, Suma de Letras, 2003.

Josu Terrnera (2003b), Madrid, La Esfera de los Libros.

ELORZA, Antonio (Coord.) (2000), La historia de ETA, Madrid, Temas de Hoy.

EZQUERRA, Iñaki, Estado de excepción. Vivir con miedo en Euskadi (2002), Barcelona, Planeta. 
FRANCESCUTTI, Luis Pablo, La pantalla profética. Cuando las ficciones se convierten en realidad (2004), Madrid, Cátedra.

GAYTAN, Esther, GIL, Fátima y ULLED, María (Eds.) (2010), Los mensajeros del miedo. Las imágenes como testigos y agentes del terrorismo, Madrid, Rialp.

GIL BERA; Eduardo (1997), Os quiero a todos, Valencia, Pre-Textos.

GIL CALVO, Enrique (2003), El miedo es el mensaje. Riesgo, incertidumbre y medios de comunicación, Madrid, Alianza Editorial.

GRUENEWALD, Armin (1984), "El Gobierno y la prensa: la seguridad nacional y el derecho público a ser informado", en MINISTERIO DEL INTERIOR, Terrorismo y medios de comunicación social, Madrid, Secretaría General Técnica del Ministerio del Interior.

GURRUCHAGA, Carmen, y SAN SEBASTIÁN, Isabel (2000), El árbol y las nueces. La relación secreta entre ETA y PNV, Madrid, temas de Hoy.

GUERRA GARRIDO, Raúl (1976), Lectura insólita del capital, Barcelona, Destino. (1990), La carta, Madrid, Espasa-Calpe. (2007) La soledad del ángel de la guarda, Madrid, Alianza Editorial.

HOFFMAN, Bruce (1999), A mano armada, Madrid, Espasa-Calpe.

IBARZABAL, Eugenio (1988), La trampa, Barcelona, Laia.

JUARISTI, Jon (1999), El bucle melancólico. Historias de nacionalistas vascos, Madrid, Espasa-Calpe.

(2000) Sacra Némesis. Nuevas historias de nacionalistas vascos, Madrid, Debolsillo. (2001) El bosque originario. Genealogías míticas de los pueblos de Europa, Madrid, Punto de Lectura. (2002) La tribu atribulada, Madrid, Espasa-Calpe. La caza salvaje, Madrid, Planeta, 2007.

LAQUEUR, Walter (1987), The Age of Terrorism, Boston, Brown. (2003) Una historia del terrorismo, Barcelona, Paidós.

MADRID, Juan (2008), Días contados, Barcelona, Norma.

MENÉNDEZ SALMÓN, Ricardo (2009), El corrector, Barcelona, Seix Barral.

MINISTERIO DEL INTERIOR (1984), Terrorismo y medios de comunicación social, Madrid, Secretaría General Técnica del Ministerio del Interior. 
MOSCOSO, Javier (2011), Historia cultural del dolor, Madrid, Taurus.

NICHOLLS, Hill (1997), La representación de la realidad. Cuestiones y conceptos sobre el documental, Barcelona, Paidós.

PABLO, Santiago de (2010), "El cine ante el terrorismo de ETA”, en Gaytán Esther, Gil, Fátima y Ulled, María, (Eds.), Los mensajeros del miedo, Madrid, Rialp, 2010.

PIZARROSO QUINTERO (2004), Alejandro, "Guerra y comunicación. Propaganda, desinformación y guerra psicológica en los conflictos armados”, en Contreras, F.R. y Sierra, F. (Coords.), Culturas de guerra, Madrid, Cátedra. (2005) Nuevas guerras, vieja propaganda: de Vietnam a Irak, Madrid, Cátedra.

RAMONET, Ignacio (2000), La golosina visual, Barcelona, Debate.

ROSÓN, Juan José (1984), "El caso de España”, en MINISTERIO DEL INTERIOR, Terrorismo y medios de comunicación social, Madrid, Secretaría General Técnica del Ministerio del Interior.

SÁNCHEZ-BIOSCA (2006), Vicente, Cine de historia, cine de memoria, Madrid, Cátedra.

SÁNCHEZ-OSTIZ, Miguel (1988), Tánger Bar, Barcelona, Círculo de Lectores. (1989), La gran ilusión, Barcelona, Anagrama.

(1992), Las pirañas, Barcelona, Seix Barral. (1995), Un infierno en el jardin, Barcelona, Anagrama. (1997) No existe tal lugar, Barcelona, Anagrama. (2000), La flecha del miedo, Barcelona, Anagrama. (2001) El corazón de la niebla, Barcelona, Seix Barral. (2002) En Bayona bajo los porches, Barcelona, Seix, Barral. (2003) Peatón de Madrid, Madrid, Espasa-Calpe. (2004) La nave de Baco, Madrid, Espasa-Calpe.

SAVATER, Fernando (2001), Perdonen las molestias, Madrid, punto de Lectura. (2003), Mira por dónde. Autobiografía razonada, Madrid, Taurus.

TORREIRO, Casimiro (2009), "Del tardofranquismo a la democracia (1969-1982)", en AAVV, Historia del cine español, Madrid, Cátedra.

TODOROV, Tzvetan (2002), Memoria del mal, tentación del bien. Indagación sobre el S.XX, Barcelona, Península. 
VERES, Luis (2000), El cielo de cemento, Barcelona, Ediciones del Bronce.

(2002) "El signo perverso: sobre lenguaje, terrorismo y práctica periodística", en Revista Latina de Comunicación Social, Tenerife, Universidad de La Laguna, n52, octubrediciembre.

(2003)“Alias y apodos en las noticias de terrorismo", en Revista Latina de Comunicación Social, Tenerife, Universidad de La Laguna, n56, marzo.

(2004a) “Terrorismo y medios de comunicación: semiótica de una simbiosis histórica”,

en Comunicación y Estudios Universitarios, Valencia, ${ }^{\circ} 12$, Universidad Cardenal HerreraCEU.

(2004b) "Prensa, poder y terrorismo", en Amnis. Revue de Civilisations Contemporaines, Brest, $\mathrm{n}^{\circ} 4$, Univesité de Bretagne Occidentale.

(2004c) “Desinformación lingüística y terrorismo", en CATALÁN, Miguel y VERES, Luis, Estrategias de la desinformación, Valencia, Generalitat Valenciana.

(2006) La retórica del terror, Madrid, Ediciones de la Torre, (2 $2^{\mathrm{a}} \mathrm{Ed}$.).

(2012) "Santiago Roncagliolo: los mitos, la metaficción y el tratamiento de la historia”, en El sentido de la metaficción. De Woody Allen a Roberto Bolaño, Madrid, Biblioteca Nueva, 2012.

WIEVIORKA, Michel (1991), El terrorismo. La violencia política en el mundo, Madrid, Plaza y Janés-Cambio 16. 